\title{
A simple device for detecting departures from visual fixation
}

\author{
MICHEL TREISMAN and S. FEARNLEY \\ Department of Experimental Psychology \\ University of Oxford, South Parks Road, Oxford OX1 SUD, Great Britain
}

\begin{abstract}
A device for detecting departures from visual fixation is described. The principle is to present control targets to one or both eyes at the projected position of the blind spot. When fixation is maintained the control target or targets are not seen. Departures from fixation manifest themselves by the reappearance of the target or targets in the visual field. The system allows approximately $1 \mathrm{deg}$ of movement or less away from the fixation point in either direction.
\end{abstract}

Perceptual experiments frequently require the control of visual fixation. This is usually achieved by providing a point or pattern to fixate. The subject's fixation accuracy and reliability can be tested by using an eyemovement monitoring system, but such instruments are often not available, or the demands imposed by the system may interfere with the experiment. Gregory (1959) described a technique for making eye movements in the dark evident by presenting a red fixation spot surrounded by a blue annulus for central fixation. This pattern was constructed from filters rear-illuminated by a small light source sufficiently dim that the blue field was invisible at the fovea but could be seen when viewed peripherally. If the subject saw it, he knew that his eye had wandered.

It is difficult to apply this technique to many display systems, such as a tachistoscope or computer-controlled oscilloscope screen; also, a fixation point other than the blue and red pattern may be desired. An alternative way to inform the subject when he departs from central fixation is to image a stimulus on the blind spot so that it is not seen when fixation is maintained but becomes visible if his eye strays. Although procedures of this sort, which do not necessarily require the subject to be in the dark, have been employed by a number of authors, they do not seem to be generally known. Feinberg (1956), working in H. L. Teuber's laboratory, used such a technique in a study of critical flicker frequency in amblyopia ex anopsia. To insure foveal fixation of the squinting eye, a spot of luminous paint, varying in size from 1 to 2 deg and mounted on a freely movable stand $260 \mathrm{~mm}$ from the subject's eye, was maneuvered until it disappeared in the subject's blind spot. Any shift in gaze brought it back to the subject's view. The subjects were examined in a dark. ened room. Teuber, Battersby, and Bender (1960) used a similar procedure when performing routine perimetry on patients with visual field defects. They placed a luminous circular patch 1 deg in diam over the area of the field into which the blind spot projected and instructed the patient to report whenever it came into view. This method was particularly helpful in cases of abnormal fixation. Johnson and Leibowitz $(1974,1976)$ and Leibowitz, Johnson, and Isabelle (1972) employed a stimulus imaged in the blind spot in a study of peripheral motion detection. The fixation stimulus was a white rectangle $.95 \times 3.80 \mathrm{deg}$ centered at $15-\mathrm{deg}$ eccentricity on the perimeter used. They found that eye movements greater than about 1 deg becams apparent immediately. Trials on which eye movements were reported were rejected.

\section{THE APPARATUS}

We describe a simple device that has been used in the light with a computer-controlled oscilloscope display, which may be employed monocularly or binocularly. The device is shown in Figure 1. The principle is to present to one or both eyes a control target positioned to project onto the blind spot when the display is properly fixated. Departures from fixation are evident to the subject because the control target reappears in his field of view. The figure shows the screen of a Tektronix 604 oscilloscope used to present computer-

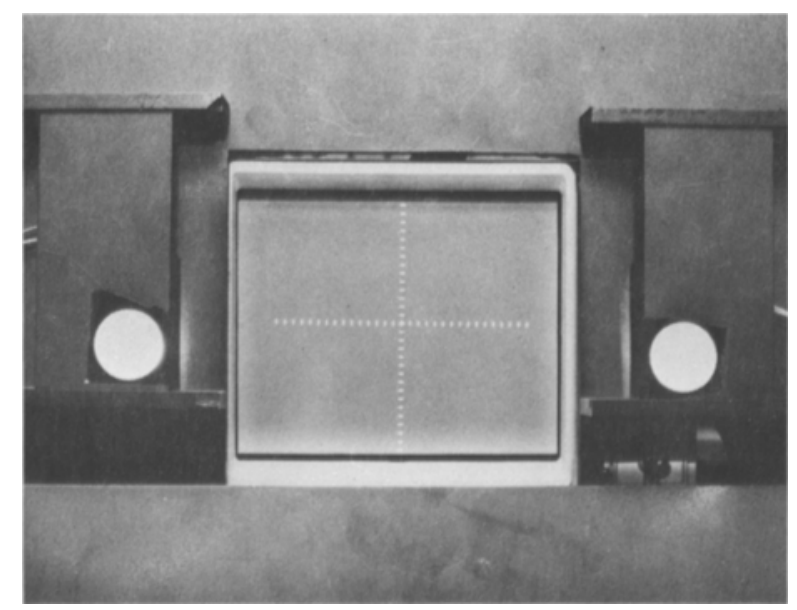

Figure 1. A photograph of the apparatus described in the text. 
Table 1

Ranges of Movement (in Degrees) Before the Target is Seen

\begin{tabular}{|c|c|c|c|c|}
\hline \multirow{2}{*}{$\begin{array}{c}\text { Direction of } \\
\text { Movement }\end{array}$} & \multicolumn{2}{|c|}{ Disk Target } & \multicolumn{2}{|c|}{ Annulus Target } \\
\hline & $\mathrm{H}^{*}$ & $V^{* *}$ & $\mathbf{H}^{*}$ & $\mathrm{~V}^{* *}$ \\
\hline Monocular & 1.4 & 2.0 & 1.7 & 2.5 \\
\hline Binocular & 1.3 & 1.8 & 1.6 & 2.4 \\
\hline
\end{tabular}

Table 2

Ranges of Movement (in Degrees) Before Target is Seen

\begin{tabular}{|c|c|c|c|c|}
\hline \multirow{3}{*}{$\begin{array}{l}\text { Direction of } \\
\text { Movement }\end{array}$} & \multicolumn{4}{|c|}{ Target } \\
\hline & \multicolumn{2}{|c|}{ Disk } & \multicolumn{2}{|c|}{ Blind Spot Mask } \\
\hline & $\mathbf{H}^{*}$ & $\mathrm{~V}^{* *}$ & $\mathrm{H}^{*}$ & $\mathrm{~V}^{* *}$ \\
\hline & 1.2 & 1.6 & 1.8 & 2.0 \\
\hline
\end{tabular}

controlled visual displays. A ground Perspex rearilluminated disk, $2.5 \mathrm{~cm}$ in diam, is shown on either side of the screen. The subject views the display from a distance of $40 \mathrm{~cm}$, at which the targets project approximately $3.6 \mathrm{deg}$. The screen is $10 \mathrm{~cm}(14 \mathrm{deg})$ high and $13 \mathrm{~cm}$ (18.5 deg) wide.

The display is viewed through a black rubber mask containing a vertical septum positioned so that each target is visible to the eye on the same side only. The septum extends $80 \mathrm{~mm}$ in front of the eye plane. The control targets are held in a frame which allows $4 \mathrm{~cm}$ of horizontal and $3 \mathrm{~cm}$ of vertical movement. The subject is asked to fixate the fixation point. Each control target, which is initially set at a low intensity, is then adjusted in position until it disappears from view. The intensity is increased until a faint glow is perceived and then again reduced until this just disappears.

To examine the accuracy of fixation, a series of vertical and horizontal bars are displayed at $1 / 2$-deg steps. The control targets are adjusted in position while the subject maintains fixation on the central cross. He is then asked to move his eye in $1 / 2$-deg steps and report whenever a target becomes visible. Two forms of control target have been used: the illuminated disk shown in the figure and an annulus with outer diam $2.5 \mathrm{~cm}$ and inner diam $2.2 \mathrm{~cm}(.2 \mathrm{deg}$ in width). When the eye wanders, the disk is seen at first appearance as a dull glow, while the annulus provides a more definite signal, the appearance of a sharp contour. The total range over which fixation may be shifted without a control target being seen has been determined for each type of target and is shown in Table 1.

Four subjects were used for each target but only one subject was common to the two groups. It is evident that the system can be set to control fixation within about 1 deg or less in either direction from the fixation point. Although subjectively the annulus gives a crisper signal when it reappears than does the disk, there is no evidence that it provides any finer control of fixation. The advantage of using two control targets rather than one is slight, if present at all.

Observations have also been made using a target designed to be roughly similar in shape to the average blind spot. This was compared with the disk, using four subjects, two of whom had served in the group previously observing the disk. In the present case, subjects viewed the display at a distance of $32 \mathrm{~cm}$, using the right eye only. At this distance the target was approximately 16 deg to the right and $2 \mathrm{deg}$ below the fixation point. The disk subtended approximately $4.6 \mathrm{deg}$ horizontally and $4.8 \mathrm{deg}$ vertically, and the blind spot target subtended approximately $3.7 \mathrm{deg}$ horizontally and $4.8 \mathrm{deg}$ vertically.

The results are shown in Table 2 . There was no apparent advantage in attempting to approximate the shape of the blind spot more exactly. This may possibly have been due to the greater total area of the disk as compared to the blind spot target.

\section{REFERENCES}

Feinberg, I. Critical flicker frequency in amblyopia ex anopsia. American Journal of Opthalmology, 1956, 42, 473-481.

GREGORY, R. L. A blue filter technique for detecting eye movements during the autokinetic effect. Quarterly Journal of Experimental Psychology, 1959, 11, 113-114.

Johnson, C. A., \& Leibowitz, H. W. Practice, refractive error, and feedback as factors influencing peripheral motion thresholds. Perception \& Psychophysics, 1974, 15, 276-280.

Johnson, C. A., \& Leibowitz, H. W. Velocity-time reciprocity in the perception of motion: Foveal and peripheral determinations. Vision Research, 1976, 16, 177-180.

Leibowitz, H. W., Johnson, C. A., \& Isabelle, E. Peripheral motion detection and refractive error. Science, 1972, 177, 1207-1208.

Teuber, H. -L., Battersby, W. S., \& Bender, M. B. Visual field defects after penetrating missile wounds of the brain. Cambridge, Mass: Harvard University Press, 1960.

(Received for publication February 13, 1976. Revision accepted July 14, 1976.) 